\title{
BMJ Open Incidence of patient safety events and process-related human failures during intra-hospital transportation of patients: retrospective exploration from the institutional incident reporting system
}

Shu-Hui Yang, ${ }^{1}$ Jih-Shuin Jerng, ${ }^{2,3}$ Li-Chin Chen, ${ }^{3}$ Yu-Tsu Li, ${ }^{3}$ Hsiao-Fang Huang, ${ }^{3}$ Chao-Ling Wu, ${ }^{4}$ Jing-Yuan Chan, ${ }^{3}$ Szu-Fen Huang, ${ }^{1,3}$ Huey-Wen Liang, ${ }^{3,5}$ Jui-Sheng Sun ${ }^{3,6}$

To cite: Yang S-H, Jerng J-S, Chen L-C, et al. Incidence of patient safety events and process-related human failures during intra-hospital transportation of patients: retrospective exploration from the institutional incident reporting system. BMJ Open 2017;7:e017932. doi:10.1136/ bmjopen-2017-017932

- Prepublication history for this paper is available online. To view these files please visit the journal online (http://dx.doi. org/10.1136/bmjopen-2017017932).

Received 26 May 2017 Revised 26 September 2017 Accepted 28 September 2017

CrossMark

For numbered affiliations see end of article.

Correspondence to

Dr Jih-Shuin Jerng; jsjerng@gmail.com

\section{ABSTRACT}

Background Intra-hospital transportation (IHT) might compromise patient safety because of different care settings and higher demand on the human operation. Reports regarding the incidence of IHT-related patient safety events and human failures remain limited.

Objective To perform a retrospective analysis of IHTrelated events, human failures and unsafe acts.

Setting A hospital-wide process for the IHT and database from the incident reporting system in a medical centre in Taiwan.

Participants All eligible IHT-related patient safety events between January 2010 to December 2015 were included.

Main outcome measures Incidence rate of IHT-related patient safety events, human failure modes, and types of unsafe acts.

Results There were 206 patient safety events in 2009 013 IHT sessions (102.5 per 1000000 sessions). Most events $(n=148,71.8 \%$ ) did not involve patient harm, and process events $(n=146,70.9 \%)$ were most common. Events at the location of arrival $(n=101,49.0 \%)$ were most frequent; this location accounted for $61.0 \%$ and $44.2 \%$ of events with patient harm and those without harm, respectively $(p<0.001)$. Of the events with human failures $(n=186)$, the most common related process step was the preparation of the transportation team $(n=91,48.9 \%)$. Contributing unsafe acts included perceptual errors $(n=14$, $7.5 \%)$, decision errors $(n=56,30.1 \%)$, skill-based errors $(\mathrm{n}=48,25.8 \%)$, and non-compliance $(\mathrm{n}=68,36.6 \%)$. Multivariate analysis showed that human failure found in the arrival and hand-off sub-process (OR 4.84, $p<0.001$ ) was associated with increased patient harm, whereas the presence of omission (OR $0.12, p<0.001$ ) was associated with less patient harm.

Conclusions This study shows a need to reduce human failures to prevent patient harm during intra-hospital transportation. We suggest that the transportation team pay specific attention to the sub-process at the location of arrival and prevent errors other than omissions. Long-term monitoring of IHT-related events is also warranted.
Strengths and limitations of this study

- Hospital-wide estimation of the incident rate of patient safety events related to intra-hospital transportation.

- Use of standardised definitions for the classification of human failures.

- Single-centre analysis, probably limiting the generalisability of the study findings.

- Probable under-reporting, as commonly perceived in real-world incident reporting.

- Probable under-detection of unsafe acts in the reported incidents.

\section{INTRODUCTION}

Intra-hospital transportation (IHT) is a commonly performed process undertaken by hospital staff during the provision of healthcare. In this situation, a patient is transported to an alternate location to obtain additional technical, cognitive or procedural care that is not available at the existing location. ${ }^{1}$ The need for IHT might be especially high for patients who receive complex interventions. This process might be challenging because it temporarily displaces the patients to other settings, such as hallways, elevators, and areas for interventions, whereas some patients who have the need for continuous medical care might be managed by staff not associated with the original care team. ${ }^{2}$ Therefore, the subject of patient safety during IHT has attracted attention in the acute critical care setting as reports have shown a variety of adverse events related to this process. ${ }^{34}$ Moreover, patients who are not critically ill might still have similar safety risks and care needs regarding equipment, staff, and process during IHT. ${ }^{5}$ Studies have reported a variety of adverse 
events during transportation, ${ }^{16-8}$ including acute deterioration of the physiologic parameters, malfunctioning of equipment and facilities, displacement and malfunctioning of indwelling tubes and lines, and other technical problems. ${ }^{9}{ }^{10}$ These reports have raised awareness of the importance of maintaining safety during this high-volume process in healthcare.

Despite this increased awareness, however, IHT-related events have appeared difficult to avoid even when a specialised transport team has undertaken the transportation. ${ }^{8}$ Explanations have included factors related to staff members ${ }^{11}$ and professional and organisational cultures. ${ }^{12}$ The intra-hospital transportation of patients might be seen as an exceptional aspect of patient care and management that almost invariably requires human participation and collaboration. Any human factor that compromises the safety barrier during the IHT process might lead to the subsequent occurrence of adverse events. Failures of a person's behaviour in relation to the process of patient care (ie, human failures) play an important part in the proximate cause of an adverse event. $^{13}$

A variety of safety domains, ${ }^{14-18}$ including healthcare, ${ }^{1319-21}$ has promoted the analysis of human failures as well as unsafe acts, the factors proximate to the adverse events. ${ }^{10}$ However, reports regarding human failures in IHT have remained limited. Difficulties underlying the scarcity of knowledge in this domain might include the temporary nature of the transportation process, the non-uniform composition of human participation, and variations in the process based on practice need. One possible solution to a deeper understanding of human failures might be the exploration of the occurrence of patient safety events through a reporting system that collects the relevant descriptive information. The objective of this study was to determine the incidence rate of IHT-related patient safety events and to investigate the modes of human failures in IHT-related events identified from the institutional incident reporting system (IRS).

\section{METHODS}

\section{Study design}

We conducted this retrospective observational study to analyse the reported IHT-associated patient safety events from January 2010 to December 2015 at the National Taiwan University Hospital (NTUH), a main university-affiliated tertiary referral medical centre in Taiwan. The Research Ethical Committee B of NTUH approved this study and waived the need for informed consent from the patients.

\section{Setting}

The NTUH is a 2300-bed, university-affiliated medical centre. The institutional IRS, established in 2000, adopted electronic reporting in 2005. The IRS provided structured data fill-in to capture necessary information as well as text entry to describe the event in detail. The staff members of the Centre for Quality Management of this hospital then performed further possible verification, information collection, and initiation of necessary improvement activities.

There was an institutional policy for IHT and a specific checklist to determine the makeup of the transportation team and equipment. When a patient needed transportation to an alternate location in the same hospital to obtain additional technical, cognitive or procedural care that was not available at the existing location, ${ }^{1}$ the staff members from the location of departure were required to complete a checklist to verify the patient's condition. Patients who had at least one of the following conditions within 8 hours before transportation were considered unstable for transportation: (1) peripheral capillary oxygen saturation $\left(\mathrm{SpO}_{2}\right)<90 \%$ shown by pulse oximetry, or apparent cyanosis if $\mathrm{SpO}^{2}$ was not available; (2) heart rate $>120 / \mathrm{min}$ or $<50 / \mathrm{min}$; (3) respiratory rate $>30 / \mathrm{min}$ or $<6 / \mathrm{min}$; (4) systolic blood pressure $<90 \mathrm{~mm} \mathrm{Hg}$ or $>220 \mathrm{~mm} \mathrm{Hg}$; (5) loss of consciousness not responding to stimulation, regardless of duration; (6) any seizures; (7) cardiac arrhythmia; (8) chest pain with cold sweats; (9) patients from the intensive care unit; (10) use of life-supporting devices such as a mechanical ventilator or cardiac support device. This was adopted from our established process of the Clinical Alert System to screen patients for unstable inpatients. ${ }^{22}$ For patients with an unstable condition defined as above, the physician at the location of departure specified the needed disciplines of the staff and the types of equipment for transportation on the list. Otherwise, the nursing staff arranged the transportation of stable patients.

The staff members then informed the staff at the location of arrival to confirm the timing for transportation. After preparation based on the checklist had been undertaken, the transportation team was assembled and the patient was transported by the team along with equipment as planned. The team needed to inform the staff of the arrival for hand-off before the procedure or intervention was performed, or before further care was provided. If the patient was transported back to the original care venue, the staff members would repeat the same process for transportation.

\section{Participants}

The investigators screened all of the reported cases to the institutional IRS during the study period for eligibility for inclusion in the analysis. Patient safety events which were associated with the IHT for patients who were at least 20 years of age were included. Based on the definitions previously described in the literature, a patient safety event was an unexpected or unintended event, which could have led to or did result in harm of the involved person. An adverse event was an injury caused during the healthcare process rather than by the underlying disease or condition of the patient. A no-harm event was an event which resulted in no harm to the person, or the effect was so minor that the person could not even feel it. A near-miss 
event was an event that may have caused accident, injury, or illness, but did not happen because of unintentional or timely intervention. ${ }^{23-26}$ Reports were excluded from the analysis if they involved transportation in a paediatric or outpatient setting, were not related to the healthcare service process, or the healthcare environment provided for the care.

\section{Analysis of the IHT process and exploration of human failures and unsafe acts}

We reviewed all available cases of incident reports in the IRS during the study period to confirm the presence of patient safety events based on the definition as described above. We then broke down the IHT process into multiple sub-process steps based on the time, location and personnel of the tasks. After that, the investigators identified and classified the modes of human failures as well as non-human failures in the events based on the report descriptions, with further classification of unsafe acts based on the definitions adopted from the literature. ${ }^{16}$ Perceptual errors were errors that occurred when faced with acting on imperfect or incomplete information. Decision errors were intended behaviours that proceeded as designed, yet the plan proved inadequate for the situation. Skill-based errors were errors that occurred as a result of little thought being shown during highly practised behaviour. Routine non-compliances were violations habitual by nature and often enabled by management that tolerated departures from the rules. Exceptional non-compliances were departures from authority, neither typical of the individual nor condoned by management. Slips were failures to properly adjust well-practised tasks that required little conscious attention to the characteristics of a new situation. Lapses were failures of memory that caused tasks not to be done. Mistakes were the selection of incorrect actions caused by misclassifying a situation or failing to take into account all of the relevant factors in a decision. ${ }^{321} 27$

\section{Data source and collection of data}

Source of the IHT-related events was from the IRS of the hospital. We retrieved the relevant data from this system regarding the location, types and detailed descriptions of the reported events to screen for IHT-related events. After the case review, the investigators collected the following data for the cases included in the analysis: date and timing of the incidents; condition of the patient based on whether the patient was stable or not on assessment before departure; the venue for patient care, departure and arrival for IHT; escort team composition; types, classifications, and outcomes of safety-related events; modes of human and non-human failures; and type of unsafe acts. For the number of transportations, we retrieved information from the registration databases from the contract worker system for intra-hospital transportation, which had recorded every session of transportation about the locations of departure and arrival, as well as the timing, but without the pertinent data for the patients.

\section{Bias}

To reduce bias, we applied a team reviewing process to analyse the incident reports in the IRS during the study period. The review team consisted of a nurse (SHY) and a doctor (JSJ) from the clinical departments and two staff members (LCC and YTL) from the Centre for Quality Management of the hospital. All of the team members had knowledge of how care was provided and how the managing processes were carried out. The reviewers independently selected the reports related to IHT and indicated its type based on the classification described below. They then determined the case selection and type classification of the incidents after reaching a consensus. The rest of the investigators then together authenticated the consensus results.

\section{Study size}

The preliminary investigation showed that the number of IHT-related events was small relative to the very large number of IHT sessions, at a frequency of about $0.01 \%$. For the purpose of statistical process control (SPC), ${ }^{28}$ the optimal period for the denominator was determined as a quarter (3 months), and this required at least 3 years to contain at least 12 data points for adequate SPC monitoring. We did not have the registered number of IHT sessions before 2010 and decided that a 6-year study period would be sufficient for this study.

\section{Quantitative variables}

In this study, we collected only categorical and nominal variables based on the entry data in the IRS. We did not choose any scaling variable for analysis. Otherwise, we chose the variables for analysis based on the investigators' consideration of the potential association between the dependent variable, such as patient harm, and possible contributing factors, such as the location of events, transportation setting, type of human failures, and type of unsafe act.

\section{Statistical analyses}

We first performed a descriptive analysis of the reported patient safety incidents during intra-hospital transport regarding the care settings, the severity of event outcomes, the types of events, modes of human failure, and the types of unsafe acts found in the IHT-related events. We then performed analyses to compare the difference for the variables regarding the presence of patient harm, physiologic change, and other relevant dependent variables.

For events with missing data in the original reporting, the investigator reviewed the detailed descriptions of the events provided by the reporters and assigned an attribute to the variables. After this review process, there were no missing data in the cases finally included in the analysis.

Results of the descriptive analysis are summarised and expressed as counts and percentage as indicated. We applied the Pearson's $\mathrm{X}^{2}$ test to compare across characteristics of the care settings. We used the SPSS 22 Software 
(SPSS Corp, Chicago, IL, USA) to perform statistical analysis. A value of $\mathrm{p}<0.05$ was considered statistically significant.

\section{RESULTS}

\section{Incidence rate of IHT-related events}

During the study period, there were 489395 admissions consisting of 3791349 patient-days for the in-patients, and 2009013 sessions of IHT performed in the hospital. Of the 17029 events reported to the IRS during the same period, we found 258 transportation-related events. We further excluded 52 cases, including 19 paediatric transportations, 18 outpatient transportations, and 15 double reporting of the same events by different employees. Therefore, we finally identified 206 IHT-related patient safety events, accounting for $1.2 \%$ of the reported incidents. The incidence rate of IHT-related patient safety events was 102.5 per 1000000 sessions of intra-hospital transportation. Available data from the report contents showed that the age of patients $(n=185)$ was $59.9 \pm 18.3$ years, and $60.3 \%$ were male. Table 1 summarises the clinical setting of these 206 events. Of the cases with safety events, the most common location of departure was the general ward (122 cases, $59.2 \%$ ), followed by the emergency room (51 cases, $24.8 \%)$. There were $53(25.7 \%)$ unstable patients transported based on the in-hospital process, including $11(5.3 \%)$ patients in the intensive care unit.

In $58(28.2 \%)$ cases, the events were associated with patient harm, including mild harm in $35(17.0 \%)$ and moderate harm in $23(11.2 \%)$. Events with moderate harm were typically an acute change of physiological status. There was no death or any cardiopulmonary resuscitation event related to the IHT process. In the events with patient harm, $62.1 \%$ occurred at the location of arrival; this was in contrast to $43.9 \%$ of the 148 events without patient harm noted at the location of arrival $(p<0.001)$. In the 32 events with physiologic changes of the patients, $21(65.6 \%)$ occurred at the location of arrival, nine (28.1\%) at halfway, and only two $(6.3 \%)$ was at the location of departure.

\section{Human failures and unsafe acts for the IHT-related events}

Table 2 summarises the modes of human failure found in the report contents for the $186(90.3 \%)$ of the 206 IHT-related events. The process step 'prepare the transport team' had most $(n=91,48.9 \%)$ of the human failures, whereas the sub-processes 'assess patient condition' $(41,22.0 \%)$ and 'assemble transport team' (32, 17.2\%) were the most frequent sub-processes with human failures. Omissions $(\mathrm{n}=91)$ during the operations, including 'sub-process not performed' $(\mathrm{n}=41)$, 'checklist fill-in not completed' $(\mathrm{n}=15)$, 'checklist sheet not provided' $(\mathrm{n}=14)$, 'equipment preparation not completed' $(n=7)$, 'team assembly not completed' $(\mathrm{n}=7)$, 'equipment checking not completed' $(\mathrm{n}=3)$, 'communication not performed' $(\mathrm{n}=2)$, 'document preparation not completed' $(\mathrm{n}=1)$, and 're-contact for change not performed' ( $\mathrm{n}=1)$, accounted for the most common (48.9\%) domain of human failures.

We further explored the unsafe acts in the 186 events with human failures and typed them according to classification, as shown in table 3 . All types of unsafe acts were present in the 186 cases, the most common being an unsafe act of non-compliance $(n=68,36.5 \%)$.

\section{Analyses of care setting and safety outcomes}

We performed univariate and multivariate analyses for possible factors related to human failures and unsafe acts that might be associated with patient harm. Table 4 shows the results of multivariate analysis for the variable with significant difference in univariate analysis. We found that human failure found in arrival and hand-off sub-process (OR 4.84, $\mathrm{p}<0.001$ ) was associated with increased patient harm, whereas the presence of omission (OR 0.12, $\mathrm{p}<0.001)$ was associated with less patient harm. In the 60 reported IHT-related events of the process step of arrival and hand-off, human failures were found in $45(75 \%)$ events, including 20 omission and 25 non-omission errors. Non-omission errors $(n=25)$ in this process step included 11 cases of inadvertent removal of line, tube or device, four cases of wrong procedure or examination performed, three cases of prolonged waiting for procedure after arrival, three cases of unexpected physiologic change, three cases of patient trauma, and one case of wrong patient transported.

We performed univariate and multivariate analyses for possible factors related to human failures and unsafe acts that might be associated with physiologic changes of the patients. Table 5 shows the results of multivariate analysis for the variable with significant difference in univariate analysis. We found that human failure occurring in the arrival and hand-off sub-process (OR 5.73, p<0.001) and the requirement for professionals in the transportation team (OR 3.31, $\mathrm{p}=0.011$ ) were associated with an increase in the physiologic changes of the patients; the presence of skill-based error (OR 0.10, $\mathrm{p}=0.001)$ and the presence of omission (OR $0.21, \mathrm{p}=0.002$ ) were associated with fewer physiologic change events.

\section{DISCUSSION}

\section{Key results}

In this study, we estimated the incidence rate of reported patient safety events during IHT and provided the observed modes of human failure for these cases. Unlike measurements with a definition of incidence rates such as patient fall, ${ }^{29}$ drug dispensing error, ${ }^{30}$ and unintended tube removal, ${ }^{31}$ reports on the incidence rate of IHT-related safety events remain scarce. Here, we recommend a standardised monitoring of the event incidence and analysis of human failures contributing to the events to better measure and improve safety for the process of IHT. 
Table 1 Clinical setting of reported patient safety events during intra-hospital transportation

\section{Care setting characteristics}

Number (\%)

Departments

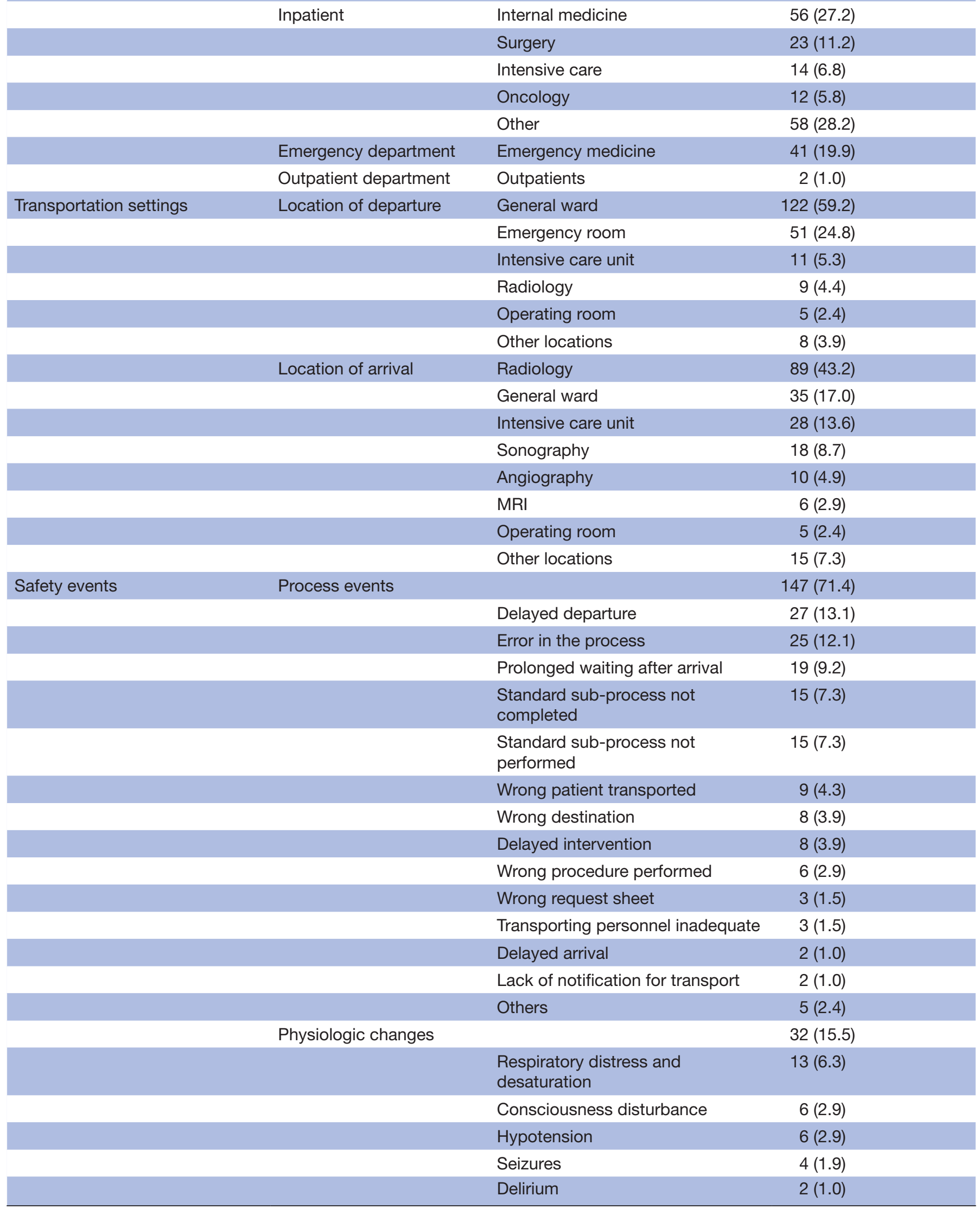




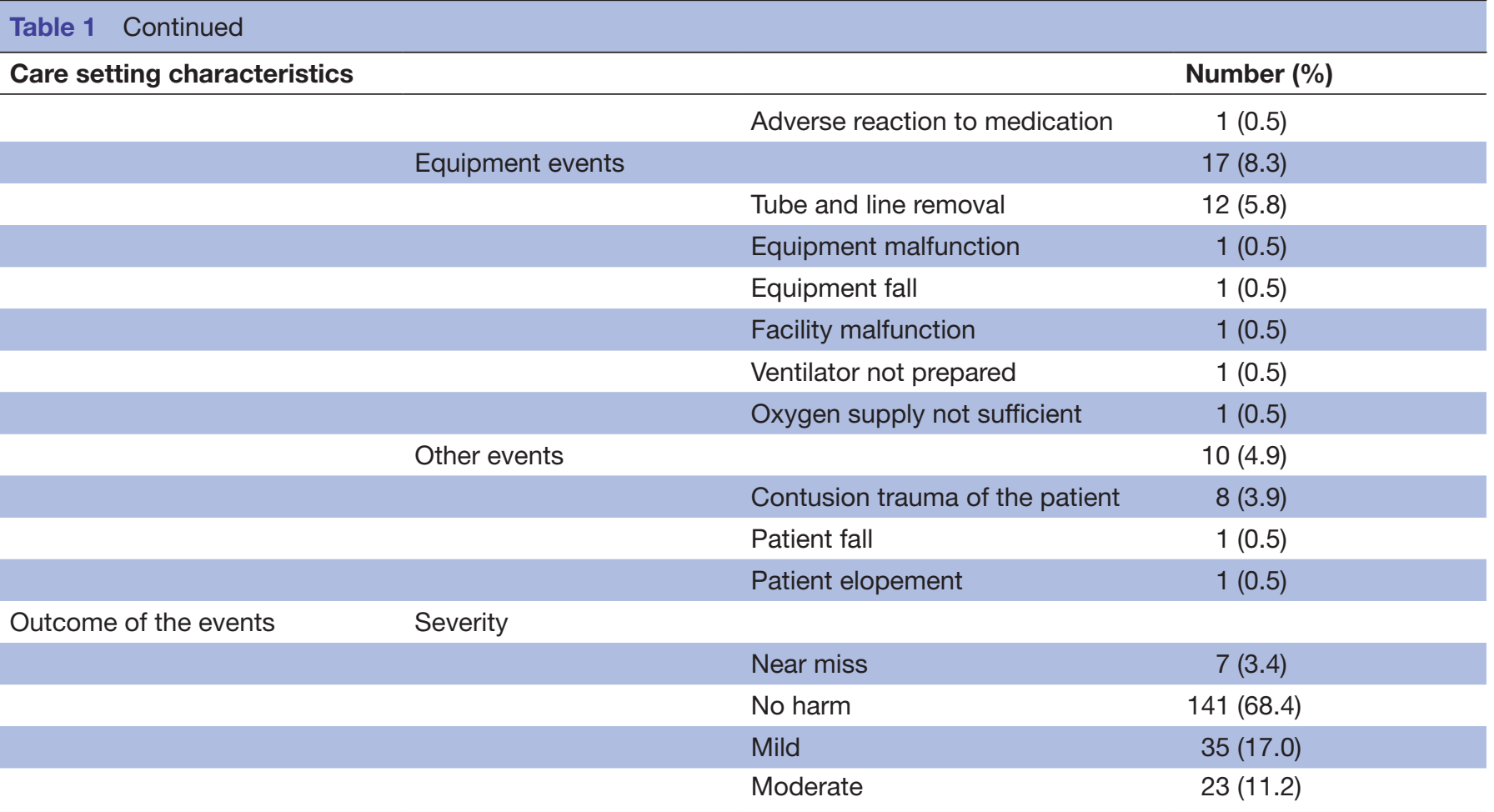

\section{Limitations}

This study had some limitations. First, the study was retrospective, and the IRS provided anonymity and did not allow the reporter to access information on patient identity. By performing content analyses of the report descriptions about the events, we could not validate the presence or absence of human failures. Nevertheless, this limitation appeared universal to the whole IRS, which should promote reporting by providing anonymity, which might encourage the reporters to describe the event in further detail as well as provide opinions and suggestions. Second, there might be a probability of under-reporting of the IHT-related events, because this category might not be the usual ones the staff members feel familiar with, especially for the staff who were not at the original care venue. This situation might require education for the staff members to engage them in event reporting. Since prospective auditing can be performed only in a selective manner, we believe that the IRS remains a valuable tool to detect and manage the problems during IHT. Third, the denominator-that is, the number of IHT sessionswas so large that the assessment of unsafe acts based on the occurrence of patient safety events during IHT might not be enough. Case-sensitive analysis might be useful instead. Fourth, we did not know if the human failure found in the reporting content was the only failure mode contributing to the event. Fifth, this was a single-centre study; thus, the generalisation of our findings requires further reports from more institutions regarding the variation of the incidence of IHT-related events and human failures depending on the definition, reporting compliance and method of analysis.

\section{Interpretations}

As technologies have advanced and the evolving patient care has become more complex, we expect an expanding number of IHTs as well as an increase of IHT-related events in the future. A standardised process for more efficient systemic reporting, monitoring, and analysis of the transportations and events are critical. Previous reports from prospective studies have shown that the incidence of adverse events during IHT of critically ill patients varied widely, ${ }^{6-8}$ and were nearly $80 \%$ in a recent prospective study. ${ }^{32}$ However, information on the incidence of adverse events during IHT of all situations was lacking. The quality and safety of non-emergency transport was discussed but mainly for the inter-hospital setting. ${ }^{5}$ Our report might provide a reference value for these purposes. Standardisation of this measurement might provide the advantages of long-term tracking within hospitals and comparisons between hospitals, as has already been seen with other commonly measured events such as falls, medication events, indwelling medical device-related events, and cardiopulmonary resuscitations.

There have been reports calling for optimisation of management during IHT to reduce patient harm. ${ }^{33}$ Examples include recommendations for patients under mechanical ventilation, ${ }^{34}$ routine and thorough equipment check and reassessment, ${ }^{35}$ written protocol, ${ }^{36}$ checklist,${ }^{37}$ teamwork approach, ${ }^{1}$ and other combinations. ${ }^{36}$ Taking these together, a comprehensive, proactive approach such as the Failure Modes and Effects Analysis (FMEA) might be of value. ${ }^{38}$ This kind of approach has been reported to be beneficial to improve safety in some fields, such as commercial aviation. ${ }^{39}$ Although FMEA has 
Table 2 Process and sub-process steps and observed failure modes of the intra-hospital transportation based on the reported IHT-related patient safety events.

\begin{tabular}{|c|c|c|c|}
\hline Process step & Sub-process step & Mode of human failure & Number (\%) \\
\hline \multirow[t]{3}{*}{ Decide to transport } & & & $7(3.8)$ \\
\hline & Confirm the need to transport & Communication not performed & $1(0.5)$ \\
\hline & Request intervention or transfer & Request error & $6(3.2)$ \\
\hline \multirow[t]{6}{*}{ Arrange transportation } & & & $34(18.3)$ \\
\hline & Contact unit of arrival & Sub-process not performed & $15(8.1)$ \\
\hline & & Task error & $10(5.4)$ \\
\hline & & Communication error & $7(3.8)$ \\
\hline & & Communication not performed & $1(0.5)$ \\
\hline & & Re-contact for change not performed & $1(0.5)$ \\
\hline \multirow[t]{17}{*}{ Prepare transport team } & & & $91(48.9)$ \\
\hline & Assess patient condition & Checklist fill-in not completed & $15(8.1)$ \\
\hline & & Checklist sheet not provided & $14(7.5)$ \\
\hline & & Sub-process not performed & $5(2.7)$ \\
\hline & & Patient assessment error & $5(2.7)$ \\
\hline & & Patient identification error & $2(1.1)$ \\
\hline & Prepare documents & Document preparation error & $2(1.1)$ \\
\hline & & Document preparation not completed & $1(0.5)$ \\
\hline & Prepare equipment & Equipment preparation not completed & $7(3.8)$ \\
\hline & & Equipment preparation error & $3(1.6)$ \\
\hline & & Equipment checking not completed & $3(1.6)$ \\
\hline & & Task error & $1(0.5)$ \\
\hline & & Sub-process not performed & $1(0.5)$ \\
\hline & Assemble transport team & Team assembly delayed & 19 (10.2) \\
\hline & & Team assembly not completed & $7(3.8)$ \\
\hline & & Task error & $3(1.6)$ \\
\hline & & Patient identification error & $3(1.6)$ \\
\hline \multirow[t]{3}{*}{ Transportation } & & & $9(4.8)$ \\
\hline & Transport the patient & Task error & $8(4.3)$ \\
\hline & & Transportation protracted & $1(0.5)$ \\
\hline \multirow[t]{7}{*}{ Arrival and hand-off } & & & $45(24.2)$ \\
\hline & Inform staff about the arrival & Sub-process not performed & $4(2.2)$ \\
\hline & Hand-off & Sub-process not performed & $16(8.6)$ \\
\hline & Displace the patient & Task error & $9(4.8)$ \\
\hline & Patient care and intervention & Task error & $15(8.1)$ \\
\hline & & Intervention delayed & $1(0.5)$ \\
\hline & & Total & 186 \\
\hline
\end{tabular}

been considered useful in the understanding of the care process, some authors have raised concerns about its validity and suggested that this methodology might need different sources of information besides the personal experience and knowledge. ${ }^{40}$ Based on our findings, we suggest that the healthcare sector might also apply this approach to investigate thoroughly the real-world human factors that might contribute to the occurrence of adverse events during IHT. The analysers might need to know the cumulative failure modes in the incident reports to understand the risks in IHT. Our findings on the failure modes of the reported cases might provide better clues for searching for the potential errors.

We addressed the importance of human failures in this study based on the premise that this realm of failures cannot be totally avoided. Human errors are to be expected, even in the best performing organisations, ${ }^{21}$ especially when staff members are nowadays 
Table 3 Unsafe acts predisposing the human failures in the 186 patient safety events during intra-hospital transportation

\begin{tabular}{|c|c|c|}
\hline $\begin{array}{l}\text { Unsafe act } \\
\text { category }\end{array}$ & Unsafe act type & Number (\%) \\
\hline Perceptual error & Perceptual error & $14(7.5)$ \\
\hline \multirow[t]{2}{*}{ Decision error } & Rule-based mistake & $28(15.1)$ \\
\hline & Knowledge-based mistake & $28(15.1)$ \\
\hline \multirow[t]{2}{*}{ Skill-based error } & Slip & $14(7.5)$ \\
\hline & Lapse & 34 (18.3) \\
\hline \multirow[t]{2}{*}{ Non-compliance } & Routine non-compliance & $62(33.3)$ \\
\hline & $\begin{array}{l}\text { Exceptional non- } \\
\text { compliance }\end{array}$ & $6(3.2)$ \\
\hline
\end{tabular}

faced with the challenges posed by rapidly paced and complex healthcare environments, typically present in the IHT process. As human factors play an important part in the healthcare system, ${ }^{20} 252641-45$ our identification of all types of unsafe acts in IHT suggests the need for deeper understanding of the human-related risks during the transportation of patients. Furthermore, while a prospective observation reported that complications and adverse events during IHT for critically ill patients was high, ${ }^{46}$ our study also included events occurring in the transportation of patients who were not critically ill because these patients might have needs similar to those of emergency patients and might have similar risks, especially when they have arrived at a different location for further care and intervention. ${ }^{47} \mathrm{~A}$ report showed that human factors contributed to $54 \%$ of the underlying causes of incidents found during IHT of critically ill patients. ${ }^{48}$ This failure might include problem recognition and judgement, adherence to protocols, patient preparation, and adequate attention, with most related to decision errors (mistake), including knowledge-based mistake and rule-based mistake. While decision errors were the most common human error in the events in our study, we also found that non-compliance accounted for a substantial proportion of these unsafe acts. This finding is comparable with a previous report that non-compliance with policies and procedures might also be important as it resulted in problems during IHT due to poor communication, inappropriate transport setting or inappropriate accompanying staff. ${ }^{49}$ Nevertheless, differences in definitions of contributing factors might provide variations of observations, but our findings suggested that these error failures might compromise patient safety during IHT.

Our analysis showed that professional participation in IHT was independently associated with increased risk of physiological change in patients during IHT. However, as the presence of professionals in the transportation team might reflect the unstable condition of the patient being transported, this finding did not imply an increased risk of physiologic change simply because of the participation of professionals in the transportation.

\section{Generalisability}

The generalisability of the study might be due to its application of process-specific risk analysis to generate failure modes. Investigators from other institutions might first examine their IHT process and break this down into sub-process steps to define the failure modes. With an IRS under proper use, the reporting contents might provide useful information

Table 4 Multivariate analyses of human factors associated with patient harm

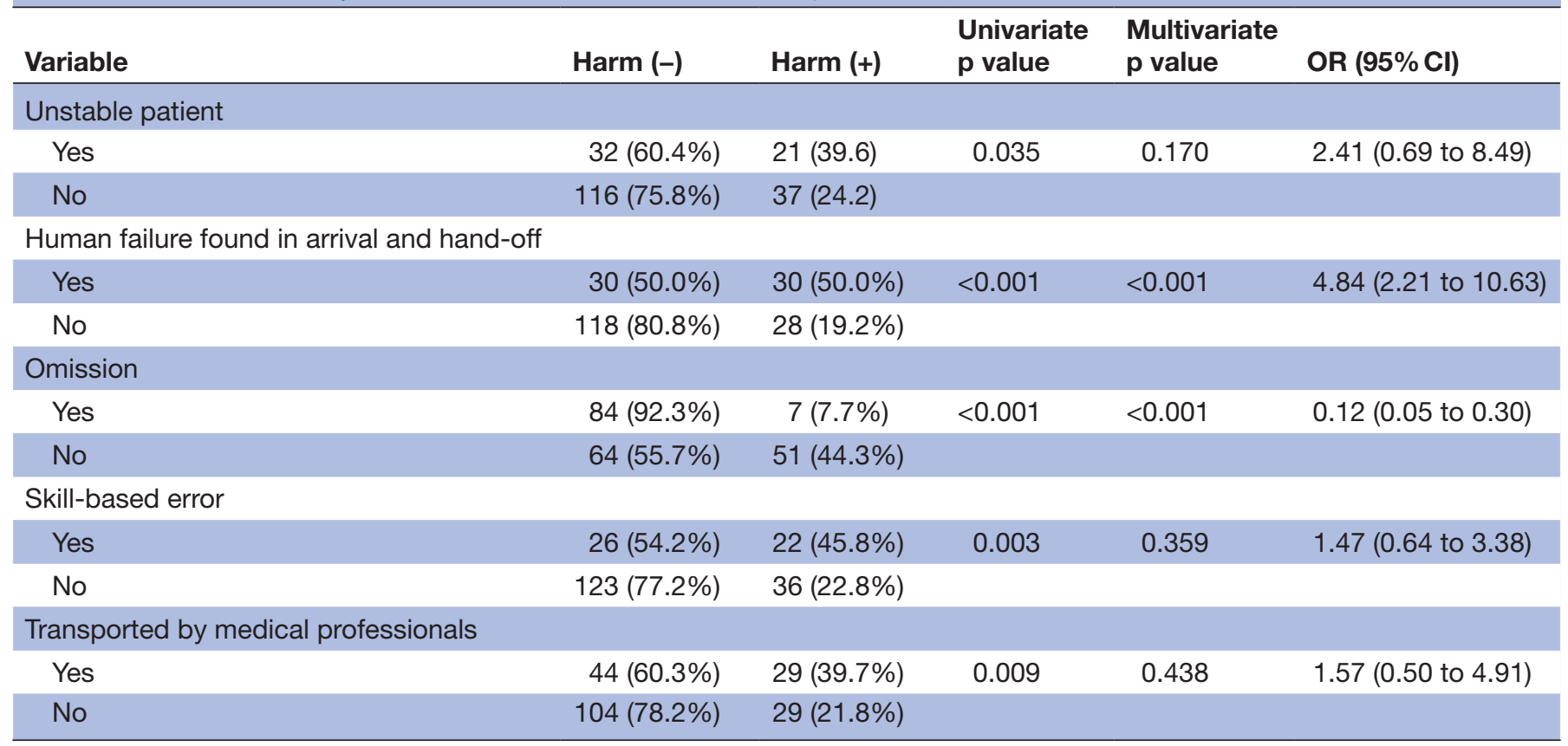


Table 5 Multivariate analyses of human factors associated with physiologic changes of the patients

\begin{tabular}{|c|c|c|c|c|c|}
\hline Variable & $\begin{array}{l}\text { Physiologic } \\
\text { change (-) }\end{array}$ & $\begin{array}{l}\text { Physiologic } \\
\text { change (+) }\end{array}$ & $\begin{array}{l}\text { Univariate } \\
\text { p value }\end{array}$ & $\begin{array}{l}\text { Multivariate } \\
\text { p value }\end{array}$ & Odds ratio $(95 \% \mathrm{Cl})$ \\
\hline \multicolumn{6}{|c|}{ Unstable patient } \\
\hline Yes & $41(77.4 \%)$ & $12(22.6 \%)$ & 0.123 & & \\
\hline No & $133(86.9 \%)$ & $20(13.1 \%)$ & & & \\
\hline \multicolumn{6}{|c|}{ Human failure found in arrival and hand-off } \\
\hline Yes & $43(71.7 \%)$ & $17(28.3 \%)$ & 0.002 & $<0.001$ & $5.73(2.20$ to 15.00$)$ \\
\hline No & $131(89.7 \%)$ & $15(10.3 \%)$ & & & \\
\hline \multicolumn{6}{|l|}{ Omission } \\
\hline Yes & $85(93.4 \%)$ & $6(6.6 \%)$ & 0.002 & 0.002 & 0.21 (0.08 to 0.58$)$ \\
\hline No & $89(77.4 \%)$ & $26(22.6 \%)$ & & & \\
\hline \multicolumn{6}{|c|}{ Skill-based error } \\
\hline Yes & $45(93.8 \%)$ & $3(6.3 \%)$ & 0.043 & 0.001 & $0.10(0.02$ to 0.40$)$ \\
\hline No & $129(81.6 \%)$ & $29(18.4 \%)$ & & & \\
\hline \multicolumn{6}{|c|}{ Transported by medical professionals } \\
\hline Yes & $55(75.3 \%)$ & $18(24.7 \%)$ & 0.009 & 0.011 & 3.31 (1.31 to 8.34$)$ \\
\hline No & 119 (89.5\%) & 14 (10.5\%) & & & \\
\hline
\end{tabular}

to detect the failure modes, especially the human failure underlying the events. Furthermore, the calculation of the number of IHT sessions might not be difficult in healthcare systems applying IT into the care practices. We suggest that once the number of hospitals reporting the incidence rate has increased, we might have a clearer picture about the occurrence of IHT-related events and process-specific human failures, providing inter-hospital comparison for improvement. As we found that the process step of arrival and hand-off carried a higher risk, while omission as human failure had a lower risk of harm, we suggest that the transportation team stress the tasks after patient arrival in relation to risk management measures. These measures might include a structured and standardised hand-off process, increased teamwork to assure safe patient displacement from the transportation vehicle, maintenance of the same level of patient care as possible, enhancement of the patient identification system, and checklist-based IHT. ${ }^{37}$

\section{CONCLUSIONS}

In conclusion, although the overall reported incidence of IHT-related patient safety events may be low, we believe that the healthcare system should apply a long-term monitoring mechanism of the incidence of these events. This study shows a need for the reduction of human failures to prevent harm to patients during IHT. We suggest that the transportation team pay specific attention to the sub-process at the location of arrival and prevent errors other than omissions.

\section{Author affiliations}

'Department of Nursing, National Taiwan University Hospital, Taipei, Taiwan
${ }^{2}$ Department of Internal Medicine, National Taiwan University Hospital, Taipei, Taiwan

${ }^{3}$ Center for Quality Management, National Taiwan University Hospital, Taipei, Taiwan ${ }^{4}$ Department of Integrated Diagnostics \& Therapeutics, National Taiwan University Hospital, Taipei, Taiwan

${ }^{5}$ Department of Physical Medicine \& Rehabilitation, National Taiwan University Hospital, Taipei, Taiwan

${ }^{6}$ Department of Orthopedic Surgery, National Taiwan University Hospital, Taipei, Taiwan

Acknowledgements The authors would like to thank Ms Li-Hong Li, Centre for Quality Management, National Taiwan University Hospital, and Mr Chien-Ta Yang, UEMS Solutions Ltd, Taiwan, for their assistance in retrieval and preparation of data.

Contributors SHY contributed to the design of the study, participated in data collection and analysis and participated in the drafting of this paper. J-SJ contributed to the design of the study, oversaw data collection, wrote the statistical analysis plan, conducted the analysis and drafted and revised the paper. L-CC assisted with the conduct of the study and participated in data collection and analysis. Y-TL assisted with the conduct of the study and participated in data collection. H-FH assisted with the conduct of the study and participated in data collection. C-LW contributed to the design of the study and assisted with the conduct of the study. J-YC oversaw the conduct of the study and commented on draft versions of the paper. S-FH oversaw the conduct of the study and commented on draft versions of the paper. H-WL oversaw the conduct of the study and commented on draft versions of the paper. J-SS oversaw the conduct of the study, contributed to the statistical analysis plan and commented on draft versions of the paper.

Competing interests None declared.

Ethics approval The Research Ethics Committee B of the National Taiwan University Hospital approved this study (\#201512054RINB) and waived the need for informed consents.

Provenance and peer review Not commissioned; externally peer reviewed.

Data sharing statement The data set is available on request from the authors: contact Jih-Shuin Jerng (jsjerng@ntu.edu.tw).

Open Access This is an Open Access article distributed in accordance with the Creative Commons Attribution Non Commercial (CC BY-NC 4.0) license, which permits others to distribute, remix, adapt, build upon this work non-commercially, and license their derivative works on different terms, provided the original work is properly cited and the use is non-commercial. See: http://creativecommons.org/ licenses/by-nc/4.0/ 
(c) Article author(s) (or their employer(s) unless otherwise stated in the text of the article) 2017. All rights reserved. No commercial use is permitted unless otherwise expressly granted.

\section{REFERENCES}

1. Warren J, Fromm RE, Orr RA, et al. Guidelines for the inter- and intrahospital transport of critically ill patients. Crit Care Med 2004:32:256-62.

2. Venkataraman ST, Orr RA. Intrahospital transport of critically ill patients. Crit Care Clin 1992;8:525.

3. Risser DT, Rice MM, Salisbury ML, et al. The potential for improved teamwork to reduce medical errors in the emergency department. Ann Emerg Med 1999;34:373-83.

4. Voigt LP, Pastores SM, Raoof ND, et al. Review of a large clinical series: intrahospital transport of critically ill patients: outcomes, timing, and patterns. J Intensive Care Med 2009;24:108-15.

5. Hains IM, Marks A, Georgiou A, et al. Non-emergency patient transport: what are the quality and safety issues? A systematic review. Int J Qual Health Care 2011;23:68-75.

6. Papson JP, Russell KL, Taylor DM. Unexpected events during the intrahospital transport of critically ill patients. Acad Emerg Med 2007;14:574-7

7. Lahner D, Nikolic A, Marhofer P, et al. Incidence of complications in intrahospital transport of critically ill patients--experience in an Austrian university hospital. Wien Klin Wochenschr 2007;119:412-6.

8. Kue R, Brown P, Ness C, et al. Adverse clinical events during intrahospital transport by a specialized team: a preliminary report. Am J Crit Care 2011;20:153-62.

9. Droogh JM, Smit M, Hut J, et al. Inter-hospital transport of critically il patients; expect surprises. Crit Care 2012;16:R26.

10. Gillman L, Leslie G, Williams T, et al. Adverse events experienced while transferring the critically ill patient from the emergency department to the intensive care unit. Emerg Med J 2006;23:858-61.

11. de Almeida ACG, Neves ALD, de Souza CLB, et al. Intra-hospital transport of critically ill adult patients: complications related to staff, equipment and physiological factors. Acta Paulista de Enfermagem 2012;25:471-6.

12. Helmreich RL. On error management: lessons from aviation. BMJ 2000;320:781-5.

13. Reason J. Understanding adverse events: human factors. Qual Health Care 1995;4:80-9.

14. Baysari MT, Caponecchia C, Mclntosh AS, et al. Classification of errors contributing to rail incidents and accidents: a comparison of two human error identification techniques. Saf Sci 2009;47:948-57.

15. Hooper BJ, O'Hare DP. Exploring human error in military aviation flight safety events using post-incident classification systems. Aviat Space Environ Med 2013;84:803-13.

16. Shappell SA, Wiegmann DA. A human error approach to aviation accident analysis: the human factors analysis and classification system. England: Ashgate Publishing, Ltd, 2012.

17. Stanton NA, Salmon PM. Human error taxonomies applied to driving: a generic driver error taxonomy and its implications for intelligent transport systems. Saf Sci 2009;47:227-37.

18. Young KL, Salmon PM. Examining the relationship between driver distraction and driving errors: a discussion of theory, studies and methods. Saf Sci 2012;50:165-74.

19. Henriksen K, Dayton E, Keyes MA, et al. Understanding adverse events: a human factors framework. In: Hughes RG, ed. Patient safety and quality: an evidence-based handbook for nurses. Rockville : Agency for Healthcare Research and Quality, 2008.

20. Hoffman RB, Segal CG, Foster JA, et al. Adaptation of the human factors analysis and classification system to patient safety studies. Proceedings of the international symposium of human factors and ergonomics in healthcare. USA:SAGE Publications; 2013.

21. Reason J. Human error: models and management. BMJ 2000;320:768-70.

22. Jerng JS, Ko WJ, Lu FL, et al. Incidence and significance of clinically abnormal events in a tertiary referral medical center: implementation of the clinical alert system (CAS). J Formos Med Assoc 2008;107:396-403.

23. Shaw R, Drever F, Hughes $\mathrm{H}$, et al. Adverse events and near miss reporting in the NHS. Qual Saf Health Care 2005;14:279-83.
24. de Vries EN, Ramrattan MA, Smorenburg SM, et al. The incidence and nature of in-hospital adverse events: a systematic review. Qual Saf Health Care 2008;17:216-23.

25. Runciman W, Hibbert $P$, Thomson R, et al. Towards an international classification for patient safety: key concepts and terms. Int J Qual Health Care 2009;21:18-26.

26. Chang A, Schyve PM, Croteau RJ, et al. The JCAHO patient safety event taxonomy: a standardized terminology and classification schema for near misses and adverse events. Int J Qual Health Care 2005;17:95-105.

27. Reason J. Human error. London: Cambridge University Press, 1990.

28. Benneyan JC, Lloyd RC, Plsek PE. Statistical process control as a tool for research and healthcare improvement. Qual Saf Health Care 2003;12:458-64.

29. Shorr RI, Mion LC, Chandler AM, et al. Improving the capture of fall events in hospitals: combining a service for evaluating inpatient falls with an incident report system. J Am Geriatr Soc 2008;56:701-4.

30. Oswald S, Caldwell R. Dispensing error rate after implementation of an automated pharmacy carousel system. Am J Health Syst Pharm 2007;64:1427-31.

31. Calvino Günther S, Schwebel C, Vésin A, et al. Interventions to decrease tube, line, and drain removals in intensive care units: the FRATER study. Intensive Care Med 2009;35:1772-6.

32. Jia L, Wang $\mathrm{H}$, Gao $\mathrm{Y}$, et al. High incidence of adverse events during intra-hospital transport of critically ill patients and new related risk factors: a prospective, multicenter study in China. Critical Care 2015;20:1-13.

33. Day D. Keeping patients safe during intrahospital transport. Crit Care Nurse 2010;30:18-32.

34. Stevenson VW, Haas CF, Wahl WL. Intrahospital transport of the adult mechanically ventilated patient. Respir Care Clin N Am 2002;8:1-35.

35. Runcie CJ, Reeve WR, Wallace PG. Preparation of the critically ill for interhospital transfer. Anaesthesia 1992;47:327-31.

36. Rice DH, Kotti G, Beninati W. Clinical review: critical care transport and austere critical care. Crit Care 2008;12:207.

37. Comeau OY, Armendariz-Batiste J, Woodby SA. Safety First! using a checklist for intrafacility transport of adult intensive care patients. Crit Care Nurse 2015;35:16-25.

38. DeRosier J, Stalhandske E, Bagian JP, et al. Using health care failure mode and effect analysis: the VA National Center for Patient Safety's prospective risk analysis system. Jt Comm J Qual Improv 2002;28:248-67.

39. Shappell S, Detwiler C, Holcomb K, et al. Human error and commercial aviation accidents: an analysis using the human factors analysis and classification system. Hum Factors 2007;49:227-42.

40. Shebl NA, Franklin BD, Barber N. Failure mode and effects analysis outputs: are they valid? BMC Health Serv Res 2012;12:150.

41. Dovey SM, Meyers DS, Phillips RL, et al. A preliminary taxonomy of medical errors in family practice. Qual Saf Health Care 2002;11:233-8.

42. Taib IA, Mclntosh AS, Caponecchia C, et al. Comparing the usability and reliability of a generic and a domain-specific medical error taxonomy. Saf Sci 2012;50:1801-5.

43. Taib IA, Mclntosh AS, Caponecchia C, et al. A review of medical error taxonomies: a human factors perspective. Saf Sci 2011;49:607-15.

44. Peebles E, Subbe CP, Hughes P, et al. Timing and teamwork--an observational pilot study of patients referred to a rapid response team with the aim of identifying factors amenable to re-design of a rapid response system. Resuscitation 2012;83:782-7.

45. Hughes AM, Sonesh S, Zajac S, et al. Leveraging HFACS to understand medication error in Emergency Medical Services (EMS). Proc Hum Factors Ergon Soc Annu Meet 2013;57:1688-92.

46. Bérubé $M$, Bernard $F$, Marion $H$, et al. Impact of a preventive programme on the occurrence of incidents during the transport of critically ill patients. Intensive Crit Care Nurs 2013;29:9-19.

47. Deasy C, O'Sullivan I. Transfer of patients--from the spoke to the hub. Ir Med J 2007;100:538-9.

48. Beckmann U, Gillies D, Berenholtz S, et al. Incidents relating to the intra-hospital transfer of critically ill patients. Intensive Care Med 2004;30:1579-85.

49. Hickey EC, Savage AM. Improving the quality of inter-hospital transfers. J Qual Assur 1991;13:16-20. 